Ottó Botond Lörinczi

Livia Hanusovszky

Petra Aradi

DOI: $10.21278 /$ TOF.40405

ISSN 1333-1124

eISSN 1849-1391

\title{
EVALUATION OF THREE DIFFERENT PHALANGEAL MOTION MEASUREMENT SYSTEMS AND DETERMINATION OF THE FUNCTIONAL RANGE OF MOTION
}

\begin{abstract}
Summary
The main contribution of this paper is the introduction of three different devices for measuring the flexion of phalangeal articulations. The devices described in the study are suitable for the determination of the active ${ }^{1}$ and the functional range of motion (ROM) of finger joints. In the paper, multiple measurements are reported in order to determine the maximum and minimum values of the active and the functional range of motion of phalangeal articulations and to validate the proper operation of the measurement devices. The first measurement method was based on the post factum image processing of video recordings, while the second and the third method used devices that were attached to the finger and equipped with analogue and digital sensors, which is similar to a miniature goniometer with a computer interface. The results showed that people only use $79-82 \%$ of the active range of motion of phalangeal articulations. Additionally, there was a $6 \%$ difference between the current measurement results and the data available from previously reported measurements. The current study also aims at finding the cause of this anomaly. Comparative analysis of the measurement results provides a basis for the future development of an actuator that would be used in a multiple finger gripper mechanism suitable for rehabilitation purposes.
\end{abstract}

Key words: $\quad$ biomechatronics, phalangeal articulations, motion analysis

\section{Introduction}

The long-term purpose of this study is to establish a base for the development of a biomimetic actuator that can be utilized in a humanoid, multiple fingered gripper mechanism. The current study deals with the active and the functional range of motion of phalangeal articulations. The features of the actuator can be optimized based on the results of these phalangeal joint measurements. The range of motion should cover the needs of everyday

\footnotetext{
${ }^{1}$ The term ,active range of motion“ refers to the limits of motion that can be performed by the muscles of an articulation. Many articulations are capable of being in different positions, but to reach these positions, an external force has to be applied in addition to the force generated by the muscles of the articulation. With respect to these positions, the articulation angle is beyond the ,active“ range.
} 
activities, and this reduced range means better conditions during device development compared to the full range of motion. It is important to state that the measurements carried out during the investigation dealt only with the kinematics of finger joints; measurements of kinetics were not part of these tests.

While there are a number of studies dealing with the structure [7], [13], [21] and analysis of the motion of phalangeal joints, the implementation of further measurements is needed. There are two main problems with the previously reported studies: the first is the data regarding the functional range of motion. The functional range of motion of joints refers to the range of motion used during everyday activities. Table 1 summarizes the functional range of motion of finger joints as it is reported in the literature [9]. Abbreviations are as follows: MCP metacarpophalangeal, PIP - proximal interphalangeal and DIP - distal interphalangeal joints.

Table 1 The functional range of motion of finger joints, basic data set [9]

\begin{tabular}{|c|c|c|c|}
\hline $\begin{array}{c}\text { Functional range of motion of } \\
\text { finger joints, Hume et al.[9] }\end{array}$ & MCP & PIP & DIP \\
\hline${\left.\text { Minimum values [ }{ }^{\circ}\right]}^{\circ}$ & 33 & 36 & 20 \\
\hline Maximum values [ $\left.{ }^{\circ}\right]$ & 73 & 86 & 61 \\
\hline
\end{tabular}

Based on the available data [9], the functional range of motion of phalangeal articulations seems to be much smaller compared to the active range of motion, especially the extended positions of fingers are not used during most of everyday tasks. Even the first test measurements carried out on the devices showed the aforementioned anomaly in the limits of the functional range of motion, thus a detailed analysis of the phenomenon was necessary.

The second problem with the standard measurements is the use of conventional protractors. During the measurement, the subject has to keep the measured articulation still while the person performing the measurement adjusts the protractor to the joint to determine its angle. It is much more useful to apply a miniature goniometer - equipped with a computer interface - that can measure the joint angle continuously during motion. Such goniometers are typically used for the measurement of lower extremity and other large articulations. A method based on image processing is also suitable for continuous measurements. However, it is essential to validate that the measurement devices and methods are accurate, in other words, the measurement results correlate with the available gold standard data sets (Figure 9). Therefore, the hypotheses of the study are as follows:

- The aim of the measurements is to evaluate the active and the functional ROM of phalangeal articulations. The measurement process is similar to those described in the literature [9], thus the results are comparable.

- The study will evaluate the accuracy of three measurement devices (a goniometer with an analogue sensor, a goniometer with a digital sensor, a marker based system). The same measurements were performed as in the literature [20] to get comparable data. In order to check this, a previously performed measurement described in the literature [20] will be repeated.

- The study will demonstrate that the limits of the functional range of motion of finger joints in the extended position are lower than it has been reported in the literature [9].

Multiple devices are available for measuring the flexion of joints. However, in the case of phalangeal joints - taking high mobility and small sizes into account - better results can be obtained by using customized measurement methods and devices compared to off-the-shelf products. In the framework of this study, multiple devices have been developed for measuring angles of phalangeal articulations. 


\subsection{Functional anatomy of fingers}

Figure 1 introduces fundamental information regarding the functional anatomy of fingers. As it can be seen, each phalanx has a flexor tendon, but for extension, a common extensor tendon is used. The focus of the current study is the measurement of joint motion, thus the marked articulations are going to be described.

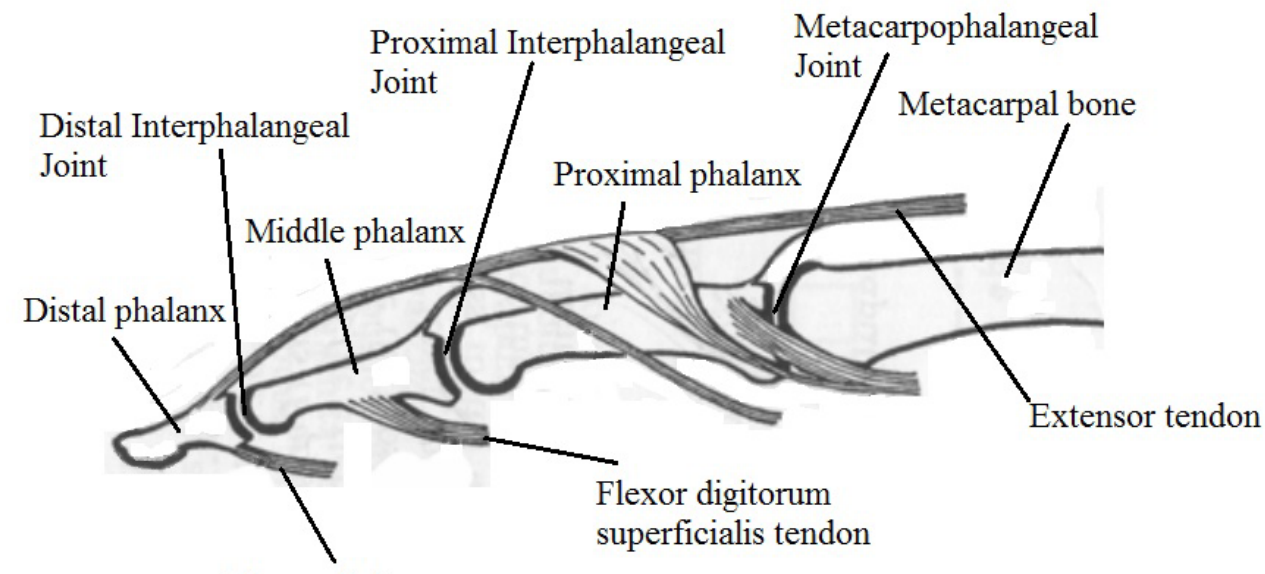

Flexor digitorum

profundus tendon

Fig. 1 Functional anatomy of the finger

The axis of rotation is always located on the bone behind the articulation. In the case of a DIP joint, it is on the middle phalanx, in the case of a PIP joint, the axis of rotation is on the proximal phalanx, and finally, the axis of the MCP joint is located on the metacarpal bone.

\section{Measurement systems and experimentation}

\subsection{Measurement devices}

Three different measurement devices were used during the investigation, and the results achieved were compared to the data published in the literature. Thus, the efficiency of the different devices was estimated. Furthermore, the accuracy of the measurements was verified, assuming that the data available from former studies is accurate.

The first measurement device was optical in nature and required markers to be placed on finger joints (Figure 2).

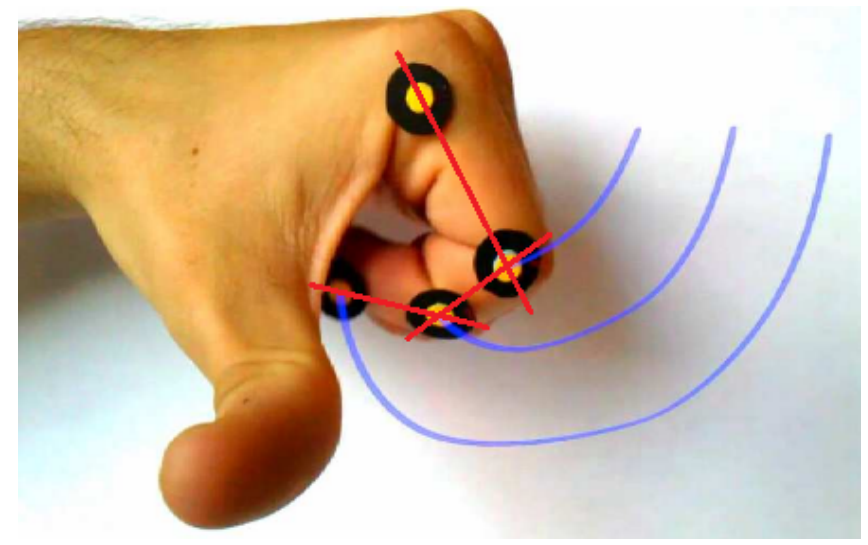

Fig. 2 Snapshot of the optical measurement 
Measurements were made via post factum image processing of video recordings. In this case, the influence on the natural motion of the finger is minimal. However, this measurement method requires lengthy preparation and a complex service apparatus compared to non-optical methods. The analysis of the movements of finger joints using markers and image processing was previously investigated by Chaudhary Nataray and Zhang [6], [17], [22], but for different purposes, e.g., control of a robotic hand using image processing. These studies apply similar experimental devices as in the case of the optical device, but the aim of the measurement is different, so there is no further correlation between the experiments.

The second device (Figure 3) was a hinge that could be attached to the finger.

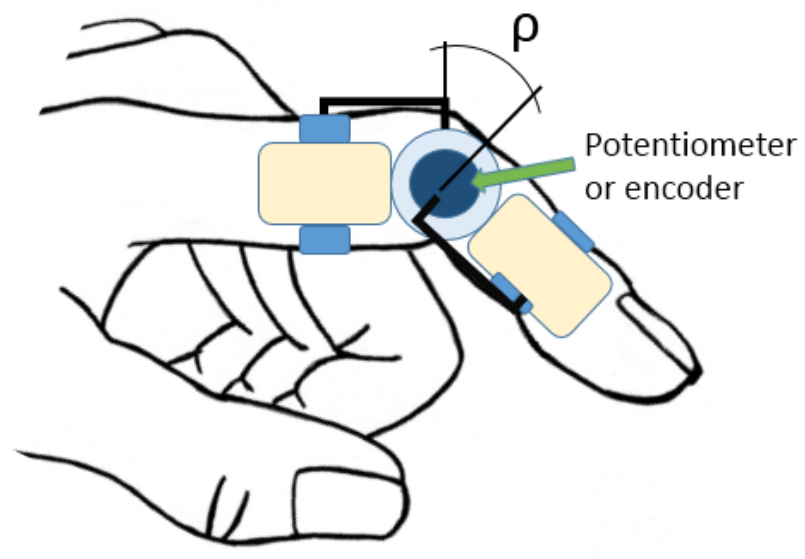

Fig. 3 Design of the finger-mounted device

This device was equipped with an analogue sensor to measure the flexion of the joint, similar to a goniometer. In former studies, different sensor sets for motion analysis are described, but in most cases, the aim is different; for example, Liu et al. developed a device for gait analysis [14], da Silva et al. studied hand postures, which are on a larger scale compared to finger articulations [19], $\mathrm{Ju}$ et al. [10] measured the tactile force and EMG signals in addition to finger angles to gain complex information on hand motion, but did not deal with the limits of angles, while Nicol [18] described an electrogoniometer, but the device is not suitable for the current study. In this device, the rotational axis of the potentiometer was aligned with the rotational axis of the finger joint to ensure accuracy of the measurement data.

The frame of the third measurement device was fairly similar to the one shown in Figure 3. However, in this device, the measurement is made with a digital sensor. With this design, the errors associated with an analogue sensor, such as measurement noise, are eliminated. Therefore, the repetitive precision is increased.

Three types of measurements were carried out with each device. First, the range of active motion of MCP, PIP and DIP joints of the index finger was investigated using all three of the aforementioned devices. The second measurement was similar to that of Thomine et al. [20] and was based on gripping a set of cylinders of different diameters and measuring the angles of each joint of the index finger. The description of the original measurement of Thomine et al. can be found in reference [20]. The purpose of the third measurement was to determine the range of motion of MCP, PIP and DIP joints of the index finger during some frequent activities of daily life. 


\subsection{Measurement subjects and procedures}

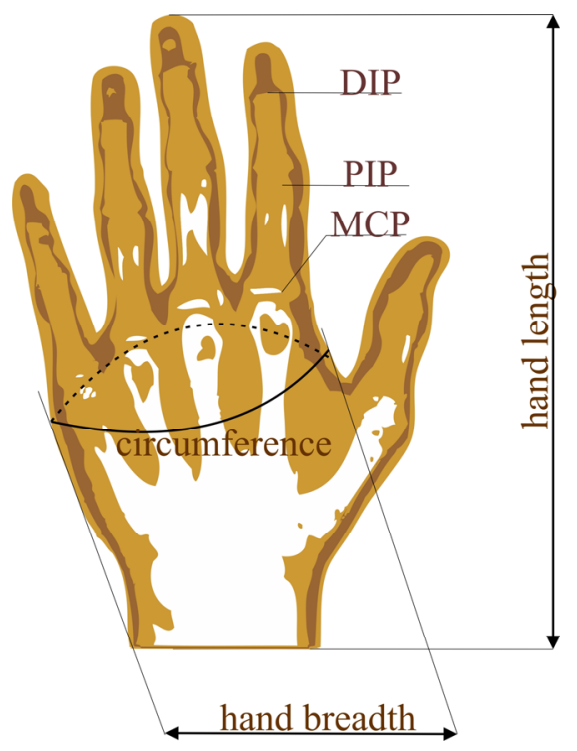

Fig. 4 Hand length, breadth and circumference

Figure 4 shows the localisation of length, breadth and circumference measurements. Participation in the measurements was voluntary. None of the subjects had a medical record of upper limb fracture. All subjects were right-hand dominant (writing with the right hand).

The numbers and characteristics of the measurement subjects can be seen in Table 2 (the data is written in the form [mean \pm Standard Deviation])

Table 2 Description of the measurement subjects

\begin{tabular}{|l|c|c|c|c|c|}
\hline & Quantity & $\begin{array}{c}\text { Age } \\
\text { /years }\end{array}$ & $\begin{array}{c}\text { Hand breadth } \\
/ \mathrm{cm}\end{array}$ & $\begin{array}{c}\text { Hand } \\
\text { length /cm }\end{array}$ & $\begin{array}{c}\text { Hand circumference } \\
/ \mathrm{cm}\end{array}$ \\
\hline Males & 11 & $32.5 \pm 7.3$ & $9.2 \pm 2.6$ & $19.1 \pm 3.6$ & $20.8 \pm 2.5$ \\
\hline Females & 9 & $33 \pm 6.9$ & $7.7 \pm 2.3$ & $17.9 \pm 3.1$ & $18.8 \pm 3.9$ \\
\hline
\end{tabular}

During each experiment, the aspect of repeatability was taken into account. The exact description of the measurements is as follows:

\subsubsection{Measurement 1:}

- The hand was in the fully extended position, and the sensor/markers were attached to the joint under investigation.

- The hand moved from the fully extended position to an entirely closed position (i.e., the hand was clenched).

Measurements can be made continuously during the motion. Thus, the measurement itself is dynamic, but the goal of the measurement was to determine the limits of the dynamic active range of motion. That is why the transition was not analysed, only the minimum and maximum values. When the image processing method was applied, all articulations of the index finger were measured simultaneously. While using an analogue or a digital sensor, the flexion of MCP, PIP and DIP joints could only be measured individually. During measurement, fully extended and fully flexed angles of the finger joints were recorded for each subject. Figures 5 and 6 show extended and clenched positions of the hand being measured. 


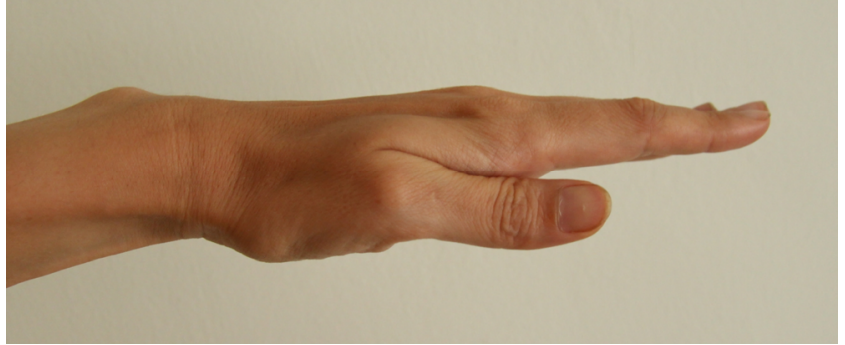

Fig. 5 The extended position

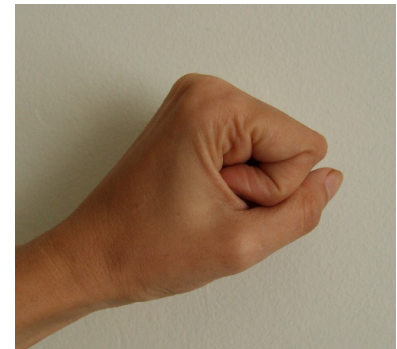

Fig. 6 The clenched position

\subsubsection{Measurement 2:}

- Each subject sequentially gripped cylinders of different diameters $(30,45,65,75$ and $80 \mathrm{~mm}$ ) while the measurement apparatus (sensor or markers) was attached to the finger. The angles of joints were registered in static states.

The goal of the measurement was the validation of the sensors. The devices are appropriate if the measurement results are in correspondence with the measurements of Thomine et al. [20]. The measured angles were compared to the initial position recorded during the first measurement. During measurement, only the flexed state of the index finger was recorded. Figure 7 shows an example of the positions being measured.

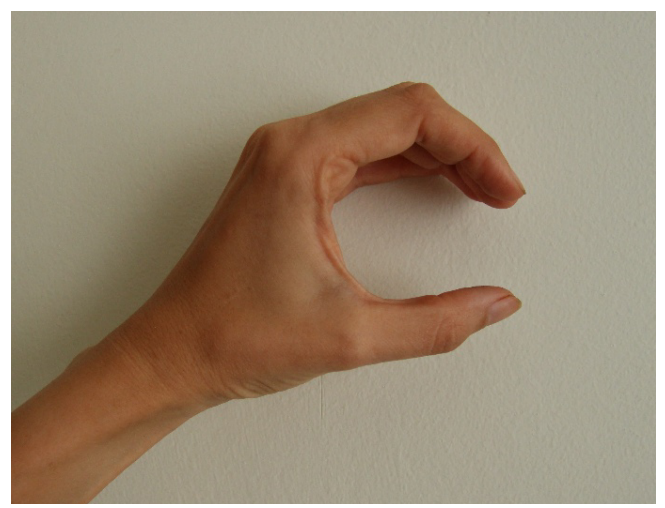

Fig. 7 Example of cylindrical gripping

\subsubsection{Measurement 3:}

The aim of the third measurement was to determine the functional range of motion of the index finger joints. Each subject performed a set of movements which are most made in everyday life, such as gripping, pinching and tapping. The measurement took the study of Ash et al. [1] regarding the main types of grip and pinch into account. During measurement, the joint angles were recorded continuously for all types of movements, and the minimum and maximum angles of the entire process were registered in accordance to the measurements reported in the literature [9]. The purpose of this measurement is similar to those carried out by Hayashi [8], except that the angles of the MCP, PIP and DIP joints of the index finger were measured here instead of the MCP joints of the hand. The following movements were carried out during the measurement:

- grasping and turning a door handle,

- writing a sentence with a ball pen,

- writing a sentence using a keyboard. 


\section{Description of data analysis}

The measurement results were analysed statistically, and different measurement methods were compared. Correlation and significance levels were determined for each combination of methods, in order to evince possible correlations between the measurements.

The statistical analysis was carried out with the statistical functions of Microsoft Excel. Finally, the measurement results were compared to available gold standard data sets.

\section{Results}

Table 3 summarizes the data acquired from Measurement 1 and shows a comparison with the data available in the literature.

Table 3 Measurement data of the active range of motion of index finger joints

\begin{tabular}{|c|c|c|c|c|c|c|c|}
\hline & \multirow{3}{*}{ Ieasurement 1} & \multicolumn{6}{|c|}{ Active range of motion $\left[^{\circ}\right]$} \\
\hline & & \multicolumn{2}{|c|}{$\mathrm{MCP}$} & \multicolumn{2}{|c|}{ PIP } & \multicolumn{2}{|c|}{ DIP } \\
\hline & & Mean & SD & Mean & $\mathrm{SD}$ & Mean & SD \\
\hline \multirow{4}{*}{ Full } & Analogue & 88.2 & 1.3 & 93.7 & 2.1 & 69.6 & 1.9 \\
\hline & Digital & 89.6 & 1.7 & 94.3 & 1.6 & 71.4 & 1.6 \\
\hline & Image & 91.7 & 2.3 & 95.8 & 2.5 & 72.4 & 2.3 \\
\hline & Literature data & 90 & - & 100 & - & 80 & - \\
\hline
\end{tabular}

Table 4 contains data acquired from Measurement 3 including the gold standard data available in the literature.

Table 4 Measurement data of the functional range of motion of index finger joints

\begin{tabular}{|c|c|c|c|c|c|c|c|}
\hline \multirow{3}{*}{\multicolumn{2}{|c|}{ Measurement 3}} & \multicolumn{6}{|c|}{ Functional range of motion of index finger joints $\left[^{\circ}\right]$} \\
\hline & & \multicolumn{2}{|c|}{$\mathrm{MCP}$} & \multicolumn{2}{|c|}{ PIP } & \multicolumn{2}{|c|}{ DIP } \\
\hline & & Mean & SD & Mean & SD & Mean & SD \\
\hline \multirow{4}{*}{$\begin{array}{l}\text { Minimum } \\
\text { values }\end{array}$} & Analogue & 9.7 & 0.8 & 11.7 & 1.5 & 5.8 & 1.2 \\
\hline & Digital & 10.1 & 0.7 & 11.8 & 1.1 & 6.5 & 1.2 \\
\hline & Image & 11.3 & 1.0 & 12.4 & 1.3 & 6.6 & 1.4 \\
\hline & Gold standard data & 33 & - & 36 & - & 20 & - \\
\hline \multirow{4}{*}{$\begin{array}{l}\text { Maximum } \\
\text { values }\end{array}$} & Analogue & 73.9 & 2.7 & 81.0 & 2.5 & 59.2 & 2.8 \\
\hline & Digital & 74.1 & 2.4 & 81.1 & 2.2 & 60.7 & 2.5 \\
\hline & Image & 75.6 & 2.5 & 82.5 & 2.6 & 61.8 & 2.9 \\
\hline & Gold standard data & 73 & - & 86 & - & 61 & - \\
\hline
\end{tabular}

In Table 5, the statistical analysis of Measurement 1 can be found, with correlations and significance levels comparing the different measurement methods. 
Table 5 Correlations and significance levels of Measurement 1

\begin{tabular}{|l|c|c|c|}
\hline & $\begin{array}{c}\text { Correlations, } \\
\text { MCP measurements }\end{array}$ & $\begin{array}{c}\text { Correlations, } \\
\text { PIP measurements }\end{array}$ & $\begin{array}{c}\text { Correlations, } \\
\text { DIP measurements }\end{array}$ \\
\hline Analog/Digital & 0.2889 & 0.3559 & 0.6941 \\
\hline Analog/Optical & 0.3662 & 0.5351 & 0.4599 \\
\hline Digital/Optical & 0.4330 & 0.3098 & 0.2659 \\
\hline & & & 0.0005 \\
\hline & $\begin{array}{c}\text { Significance levels, } \\
\text { MCP measurements }\end{array}$ & $\begin{array}{c}\text { Significance levels, } \\
\text { PIP measurements }\end{array}$ & $\begin{array}{c}\text { Significance levels, } \\
\text { DIP measurements }\end{array}$ \\
\hline Analog/Digital & 0.0244 & 0.0247 & 0.0001 \\
\hline Analog/Optical & 0.0244 & $6.24701 \mathrm{E}-05$ & $1.15449 \mathrm{E}-06$ \\
\hline Digital/Optical & 0.0136 & 0.0116 & 0.005 \\
\hline
\end{tabular}

Figure 8 also shows the correlation between the different methods.

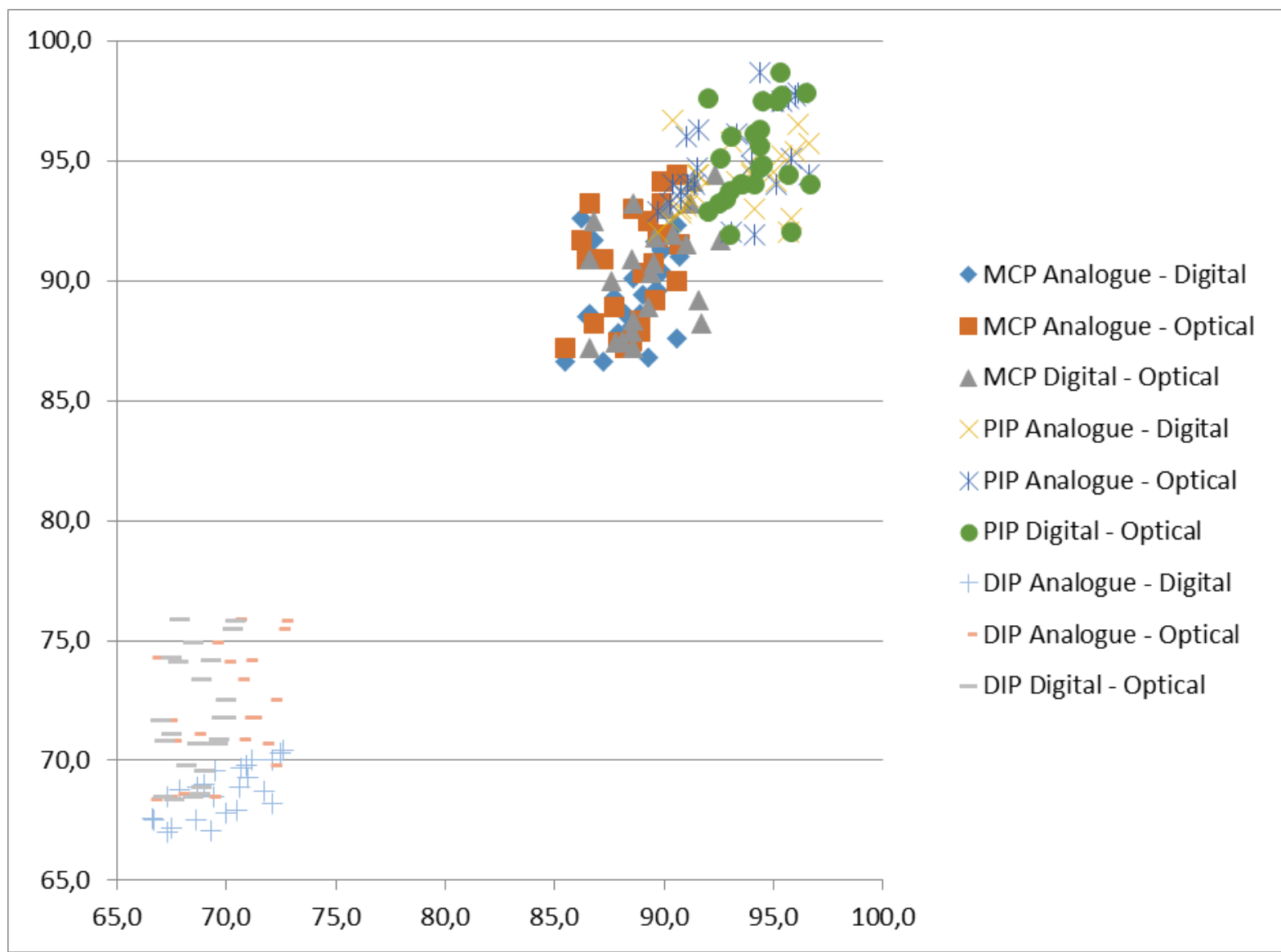

Fig. 8 Correlation between different methods (Measurement 1)

The results of Measurement 2 are shown in Table 6, which also presents data from the study of Thomine et al. [20] for comparison. 
Determination of the Functional Range of Motion

Table 6 Results and mean percentile accuracy compared to gold standard data set, Measurement 2

\begin{tabular}{|c|c|c|c|c|}
\hline Thomine, $^{\circ}$ & Digital, $^{\circ}$ & Analogue, $^{\circ}$ & Optical, $^{\circ}$ & Cylinder diameters, $\mathrm{mm}$ \\
\hline 78 & 74 & 70 & 76 & 30 \\
\hline 65 & 62 & 59 & 60 & 45 \\
\hline 53 & 53 & 53 & 53 & 65 \\
\hline 48 & 47 & 51 & 49 & 75 \\
\hline 44 & 41 & 45 & 45 & 80 \\
\hline- & 3.72 & 5.62 & 2.94 & Mean percentile accuracy, $\%$ \\
\hline
\end{tabular}

Since the measurements of Thomine et al. [20] had been carried out with standard methods, the data set provided by those measurements can now be considered as the gold standard data set in the evaluation of the results of this study. Table 6 also indicates the mean percentile accuracy of each method compared to the gold standard data set. Figure 9 also describes the results of Measurement 2.

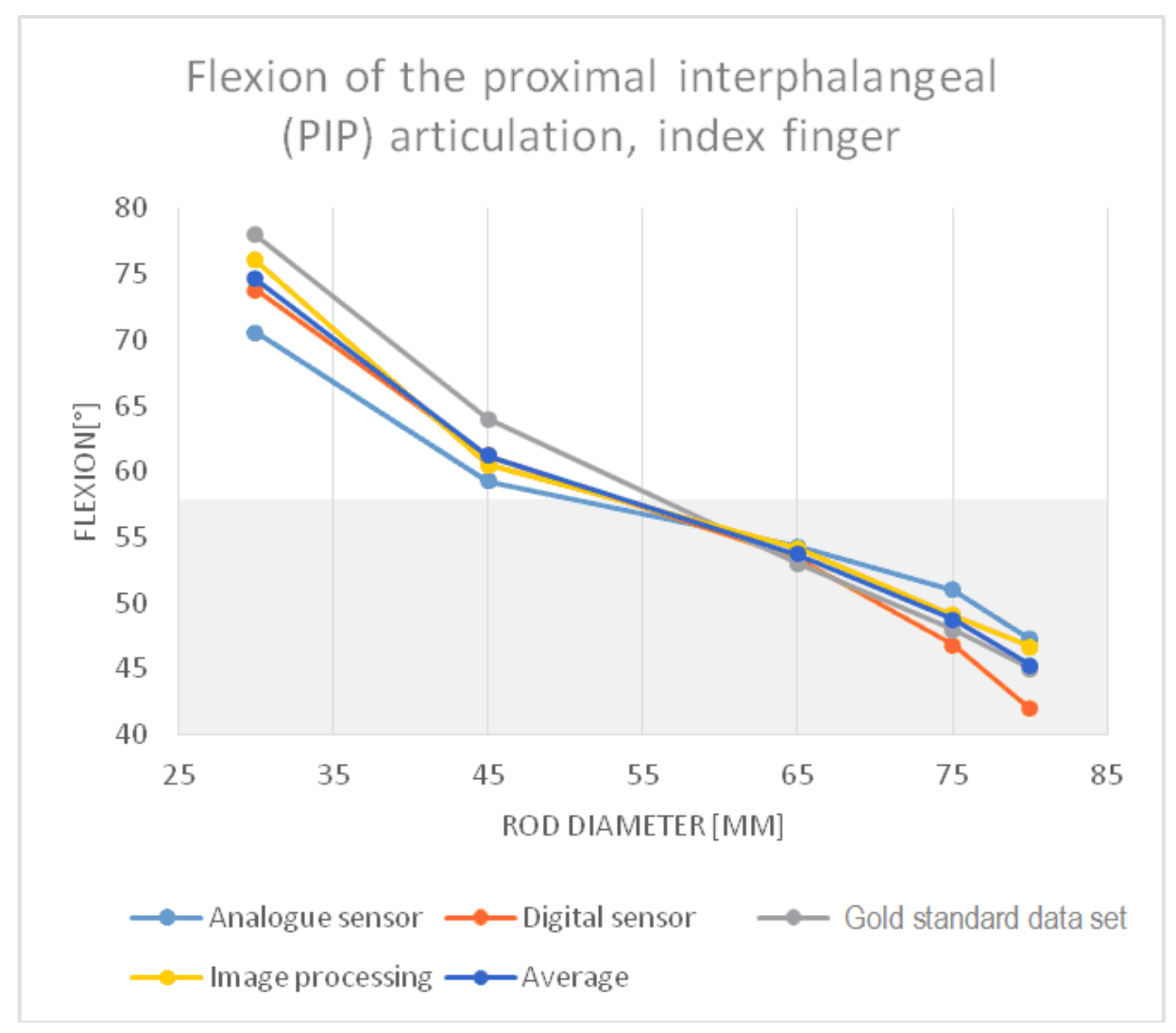

Fig. 9 PIP joint angles measured with different devices evaluated against gold standard data set (Measurement 2)

The statistics, including the correlations and significance levels of the results of Measurement 3 , are presented in Table 7 . 
Table 7 Correlations and significance levels of Measurement 3

\begin{tabular}{|c|c|c|c|c|c|c|}
\hline & \multicolumn{2}{|c|}{ MCP measurements } & \multicolumn{2}{c|}{ PIP measurements } & \multicolumn{2}{c|}{ DIP measurements } \\
\hline & $\begin{array}{c}\text { Correlation, } \\
\text { extended }\end{array}$ & $\begin{array}{c}\text { Correlations, } \\
\text { flexed }\end{array}$ & $\begin{array}{c}\text { Correlation, } \\
\text { extended }\end{array}$ & $\begin{array}{c}\text { Correlations, } \\
\text { flexed }\end{array}$ & $\begin{array}{c}\text { Correlation, } \\
\text { extended }\end{array}$ & $\begin{array}{c}\text { Correlations, } \\
\text { flexed }\end{array}$ \\
\hline $\begin{array}{c}\text { Analogue/ } \\
\text { Digital }\end{array}$ & 0.1920 & 0.6359 & 0.3544 & 0.5831 & 0.4978 & 0.4421 \\
\hline $\begin{array}{c}\text { Analogue/ } \\
\text { Optical }\end{array}$ & 0.3605 & 0.6381 & 0.4245 & 0.2568 & 0.2926 & 0.5367 \\
\hline $\begin{array}{c}\text { Digital/ } \\
\text { Optical }\end{array}$ & 0.6275 & 0.4880 & 0.3667 & 0.2818 & 0.4242 & 0.3375 \\
\hline & $\begin{array}{c}\text { Significance } \\
\text { levels, } \\
\text { extended }\end{array}$ & $\begin{array}{c}\text { Significance } \\
\text { levels, } \\
\text { flexed }\end{array}$ & $\begin{array}{c}\text { Significance } \\
\text { levels, }\end{array}$ & $\begin{array}{c}\text { Significance } \\
\text { levels, } \\
\text { flexed }\end{array}$ & $\begin{array}{c}\text { Significance } \\
\text { levels, } \\
\text { extended }\end{array}$ & $\begin{array}{c}\text { Significance } \\
\text { levels, } \\
\text { flexed }\end{array}$ \\
\hline $\begin{array}{c}\text { Analogue/ } \\
\text { Digital }\end{array}$ & 0.0444 & 0.0010 & 0.2021 & 0.0024 & 0.0005 & 0.0055 \\
\hline $\begin{array}{c}\text { Analogue/ } \\
\text { Optical }\end{array}$ & $1.57 \mathrm{E}-09$ & $1.18 \mathrm{E}-09$ & 0.3065 & $1.63 \mathrm{E}-09$ & 0.0044 & $1.67 \mathrm{E}-05$ \\
\hline $\begin{array}{c}\text { Digital/ } \\
\text { Optical }\end{array}$ & $2.86 \mathrm{E}-09$ & $3.02 \mathrm{E}-06$ & 0.0761 & $3.83 \mathrm{E}-08$ & 0.2830 & 0.0329 \\
\hline
\end{tabular}

The correlation between the results measured with the different methods is presented in Figure 10 for the minimum values and in Figure 11 for the maximum values.

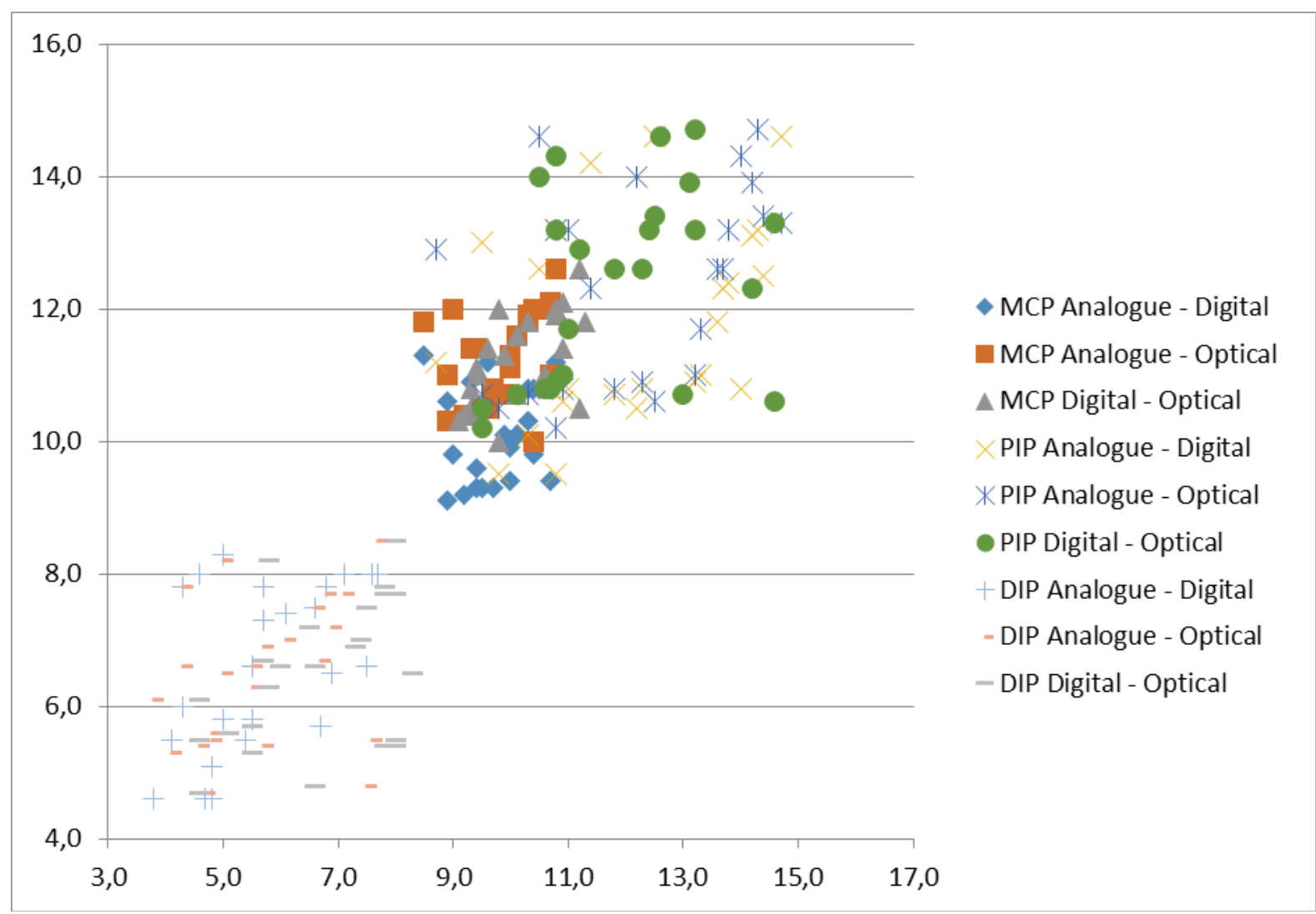

Fig. 10 Correlation between different methods, minimum values (Measurement 3) 


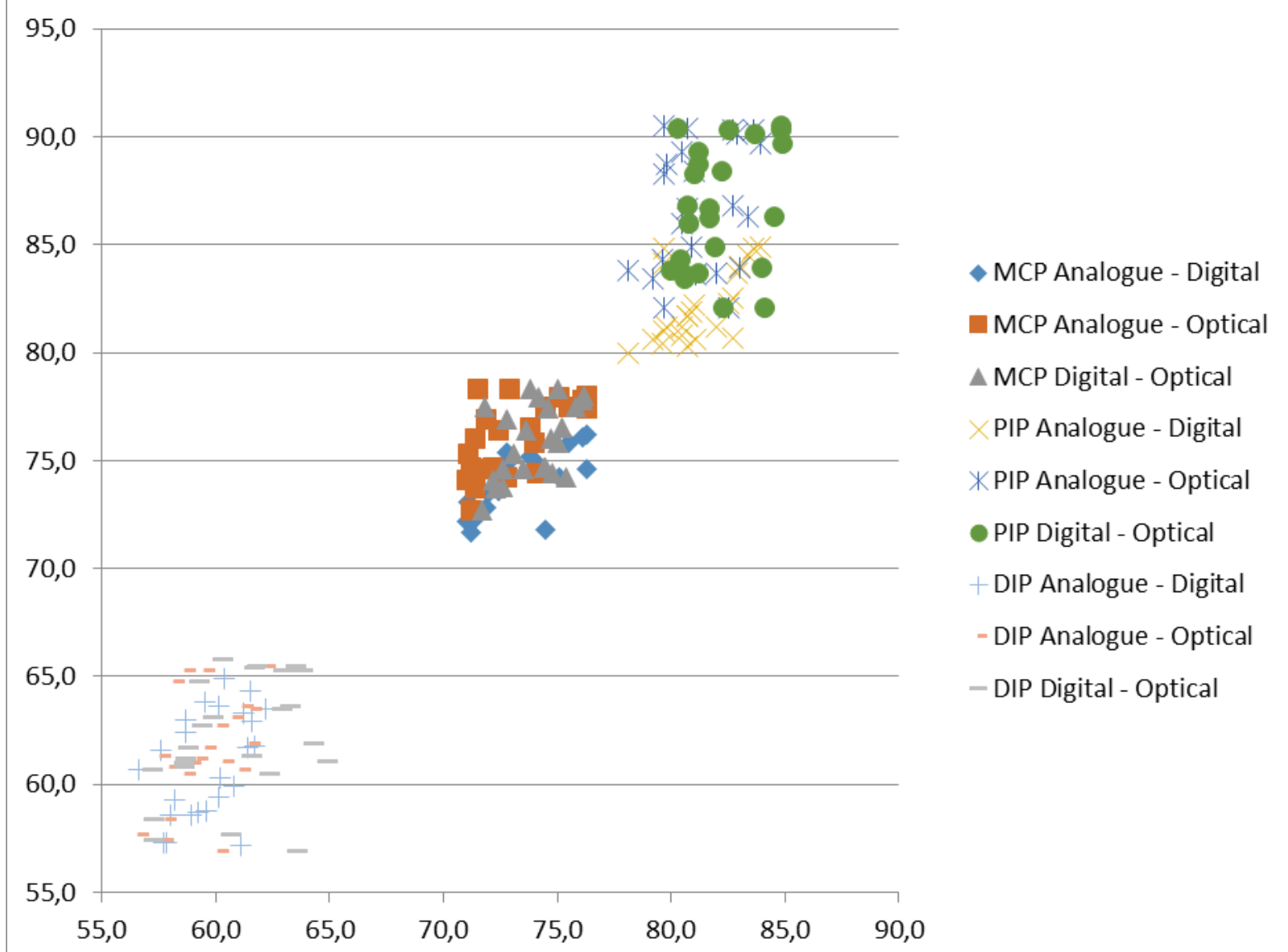

Fig. 11 Correlation between different methods, maximum values (Measurement 3)

The gold standard data set for this measurement can be found in the literature [9]. The angular and percentile differences between the active and the functional range of motion of the MCP, PIP and DIP joints are given in Table 8.

Table 8 Angular and percentile differences between the active and the functional range of motion of MCP, PIP and DIP joints, index finger

\begin{tabular}{|c|c|c|c|}
\hline & MCP joint & PIP joint & DIP joint \\
\hline Active range of motion (from $0^{\circ}$ ) & 89.8 & 94.6 & 71.1 \\
\hline $\begin{array}{c}\text { Functional range of motion, } \\
\text { minimum }\end{array}$ & 10.4 & 12 & 6.3 \\
\hline $\begin{array}{c}\text { Functional range of motion, } \\
\text { maximum }\end{array}$ & 74.5 & 81.5 & 60.6 \\
\hline $\begin{array}{c}\text { Difference between active and } \\
\text { functional ranges, \% }\end{array}$ & 28.6 & 26.5 & 23.6 \\
\hline
\end{tabular}

\section{Discussion}

Regarding Measurement 2, the results show approximately a $6 \%$ difference between the results found in the literature and the results of the current measurements, especially for the cases of cylinders with the smallest and largest diameters. However, it is conspicuous that the results are almost identical for all methods for the measurements performed with $60-65 \mathrm{~mm}$ cylinders. The measurements of Thomine et al. [20] were based on manual processing of 
X-ray images, where the angles of joints were determined by using protractors [20]. This procedure is widely used today, although the acquisition of such images requires even more complex equipment than the image processing using markers. In addition, the hand has to be in a proper position for the image to be taken, which can introduce anomalies compared to the natural hand posture; however, the accuracy of data has to be validated or a new gold standard data set has to be defined. This is the most likely reason for the discrepancies between the measurement results of Thomine et al. [20] and the results obtained by applying the three methods described here for gripping small and large diameter cylinders. Taking the small anomaly between the gold standard data set and the current measurement into account, it can be stated that the devices are suitable for joint angle registration, thus the first and the second hypothesis in the introduction section are proved. The study of Bae et al. [2] also had a maximum error of $5.44^{\circ}$, which corresponds to a relative error of approximately $7 \%$.

The attachment of equipment to the fingers is an easy-to-use solution with respect to the measurement data acquisition. However, these devices also have effect on the movements of the hand and can only be used to make reliable measurements in specific cases, in which the natural motion of fingers is not disturbed. From this point of view, the optimal method is image processing, but such measurements require complex equipment and high computing capacity for the post-processing. Literature sources often do not provide details on the measurement device applied and its possible effects on the natural motion of finger joints [9], [12], [16], [20]. Furthermore, publications addressing the accuracy of joint motion measurements [3], [4], [5], [11], [15] do not provide detailed information on the quantitative analysis of the motion of metacarpophalangeal and interphalangeal articulations. This knowledge gap can be eliminated by merging the results of the above two fields of study and by creating an accurate and complete measurement set.

Additionally, it could be said that the most important aspect is the relationship between the limits of the active joint motion and the functional range of motion that is required during everyday activities. It is important to mention that the maximum angles measured are very close to the available gold standard data, but the minimum angles show great differences. The cause of this phenomenon is that the former study [9] does not involve typing on a keyboard, which is one of the most important everyday activities in the present time. During typing, finger joints are frequently unbent, which causes lower minimum values, thus the third hypothesis in the introduction section is proved. Based on the measurements made here, the angles measured during the daily routine had a higher minimum and a lower maximum compared to the active range of the joint motion, and the differences varied between $18-21 \%$. The quantitative analysis of the typical range of motion of the index finger joints showed that the active range of motion is at least $18 \%$ larger compared to the range of motion necessary for everyday life.

Regarding the results of the statistical analyses, it can be stated that there seems to be moderate correlation between the different measurement methods, but the level of correlation is low, just like in the case of the significance levels. The correlation levels might be distorted and decreased by the measurement noise and by the fact that the multiple change of devices during measurement could highly influence the correlations. The largest correlation levels usually occur between digital and analogue goniometers, while the optical method does not show the same correlation. This can be caused by the difference between the measurement principles.

With regards to the measurement results, certain circumstances set a limit to this study. First, it was not possible to perform the measurements on a large number of subjects. Therefore, a lack of diversity reduces the reliability of the measured data. Another important aspect is the accuracy of the measurement devices. The characteristics of the measurement 
devices were determined, but no official validation was performed, which also reduces the reliability. Nevertheless, the measured data agrees well with that of previous studies.

To conclude the inferences based on the measurements, it can be said that

- the devices described in the study are suitable for the determination of angles of phalangeal joints,

- the measurements showed that the active range of motion is approximately $20 \%$ larger than the range necessary for everyday activities, and

- to gain complete knowledge, a new set of measurements should be developed, and an improved version of the measurement device (e.g. with the capability of measuring multiple articulations at the same time) should be implemented.

\section{Further development}

The measurements reported in the study will be carried out on left hand dominant subjects also, in order to determine differences between the active and the functional range of motion of phalangeal articulations of the left and the right hand.

In the near future, biomimetic actuators will be produced with an optimized range of motion based on the results of this investigation. Also, based on the results of these measurements, a multiple fingered gripper will be produced that is capable of accurately imitating the motion of a real hand. Consideration will be given to whether a full range of motion should be taken into account or if only a limited range corresponding to the motion during daily activities should be considered if the difficulty of implementation imposes limitations. From the perspective of rehabilitation, optimal characteristics of physiotherapy can be estimated based on the measurement results. Additionally, the progress of rehabilitation can be evaluated based on similar measurements that would regularly be performed on patients.

\section{Acknowledgements}

We would like to express our thanks to Mr. Barnabás Kecskés for his help in performing the measurements and implementing the device equipped with a digital sensor and to Mr. Attila Bojtos for making the analogue goniometer available to us.

\section{REFERENCES}

[1] Ash, H. E., T. J. Joyce and A. Unsworth: Biomechanics of the Distal Upper Limb, Current Orthopaedics, 10(1):25-36, 1996. DOI:10.1016/S0268-0890(96)90067-5

[2] Bae, S. and T. J. Armstrong: A Finger Motion Model for Reach and Grasp, International Journal of Industrial Ergonomics 41:79-89, 2011. DOI:10.1016/j.ergon.2010.11.001

[3] Brannon, E. W,G. Klein: Experiences with a Finger-joint Prosthesis. Journal of Bone and Joint Surgery [Am], 41(1):87-102. 51, 1959.

[4] Bruton, A.: Comparison of Visual Estimation and Goniometry for Assessment of MCP Joint Angle. Physiotherapy, 85, 1999.

[5] Burr, N. and A. L. Pratt: Inter-rater and Intra-rater Reliability when Measuring Interphalangeal Joints. Physiotherapy, 51:641-652, 2003. DOI:10.1016/S0031-9406(05)60097-1

[6] Chaudhary A. and J. Raheja: Bent Fingers' Angle Calculation using Supervised ANN to Control, Computers and Electrical Engineering, 39:560-570,2013. DOI:10.1016/j.compeleceng.2012.07.012

[7] Hahn, P., A. Hradetzky and U. Lanz: Quantitative Analysis of the Linkage Between the Interphalangeal Joints of the Index Finger: An in Vivo Study, The Journal of Hand Surgery: British \& European Volume, 20(5):696-699. 1995. DOI:10.1016/S0266-7681(05)80139-1

[8] Hayashi, H, H. Shimizu: Essential Motion of Metacarpophalangeal Joints During Activities of Daily Living. Journal of Hand Therapy Volume 26(1):69-74, 2013. DOI:10.1016/j.jht.2012.10.004 
[9] Hume, Mary C., Harris Gellman, MD, Harry McKellop, PhD, Robert H. Brumfield Jr., MD: Functional range of motion of the joints of the hand. The Journal of Hand Surgery 15(2):240-243, 1990. DOI:10.1016/0363-5023(90)90102-W

[10] Ju, Z. and H. Liu: Human Hand Motion Analysis With Multisensory Information. IEEE/ASME Transactions on Mechatronics, 19(2):456-466, 2014. DOI:10.1109/TMECH.2013.2240312

[11] Kato, M., A. Echigo and H. Ohta: The Accuracy of Goniometric Measurements of PIP joints in Fresh Cadavers. J Hand Ther, 2007(20):12-19, 2007. DOI:10.1197/j.jht.2006.11.015

[12] Lee, J. W., K. Rim: Measurement of Finger Joint Angles and Maximum Finger Forces During Cylinder Grip Activity, J Biomed Eng. 13(2):152-62., 1991. DOI:10.1016/0141-5425(91)90062-C

[13] Levangie, P. K, C. C. Norkin, Joint Structure and Function - A Comprehensive Analysis 4th ed. FA Davis, Philadelphia, 2005.

[14] Liu, T., Y. Inoue and K. Shibata: Development of a Wearable Sensor System for Quantitative Gait Analysis. Measurement 42:978-988, 2009. DOI:10.1016/j.measurement.2009.02.002

[15] Macionis, V.: Reliability of the Standard Goniometry and Diagrammatic Recording of Finger Joint Angles: a Comparative Study with Healthy Subjects and Nonprofessional Raters, BMC Musculoskeletal Disorders, 14:17, 2013. DOI:10.1186/1471-2474-14-17

[16] Mallon, W.J, H. Brown, J. Nunley, Digital ranges of motion: Normal values in young adults. The Journal of Hand Surgery Am, 16:882-887. 1991. DOI:10.1016/S0363-5023(10)80155-8

[17] Nataraj, R. and Z-M. Li: Robust Identification of Three-Dimensional Thumb and Index Finger Kinematics With a Minimal Set of Markers,J. Biomech Eng 135(9):091002, 2013. DOI:10.1115/1.4024753

[18] Nicol, A.: A New Flexible Electrogoniometer with Widespread Applications. Biomechanics: Human Kinetics. 1029-1033. Illinois, 1987.

[19] da Silva, A. F.: FBG Sensing Glove for Monitoring Hand Posture. IEEE Sensors Journal, 11(10):2442 2448, 2011. DOI:10.1109/JSEN.2011.2138132

[20] Thomine, J-M., N. Biga \& Y. Gibon: Étude Biométrique de la Flexion des Articulations Digitalesdes Doigts Longs dans les Prises, Ann. Chir. Main, 4(2):156-165. 1985. DOI :10.1016/S07539053(85)80128-9

[21] Tubiana, R, J-M. Thomine, E. Mackin, Examination of the Hand and Wrist.2nd ed. St. Louis, CV Mosby, 1996.

[22] Zhang, X. and S-W. Lee: Determining Finger Segmental Centers of Rotation in Flexion-extension Based on Surface Marker Measurement, Journal of Biomechanics, 36:1097-1102, 2003. DOI:10.1016/S0021-9290(03)00112-X

$\begin{array}{ll}\text { Submitted: } & 30.7 .2015 \\ \text { Accepted: } & 20.9 .2016\end{array}$

Ottó Botond Lőrinczi

Petra Aradi

Lívia Hanusovszky

Budapest University of Technology and

Economics, Department of Mechatronics, Optics and Engineering Informatics,

Bertalan Lajos street 4-6,

1111, Budapest, Hungary 